\title{
Schimke immuno-osseous dysplasia
}

INSERM

\section{Source}

INSERM. (1999). Orphanet: an online rare disease and orphan drug data base. Schimke immuno-osseous dysplasia. ORPHA:1830

Schimke immuno-osseous dysplasia (SIOD) is a multisystem disorder characterized by spondyloepiphyseal dysplasia and disproportionate short stature, facial dysmorphism, Tcell immunodeficiency, and glomerulonephritis with nephrotic syndrome. 